\title{
Cross-sectional survey of depressive symptoms and suicide-related ideation at a Japanese national university during the COVID-19 stay-home order
}

Kyoko Nomura ${ }^{1 *}$ (D), Sachiko Minamizono ${ }^{1}$, Eri Maeda ${ }^{1}$, Roseline Kim¹, Toyoto Iwata ${ }^{1}$, Junko Hirayama ${ }^{1}$, Kyoichi Ono ${ }^{2}$, Masahito Fushimi ${ }^{3}$, Takeshi Goto ${ }^{3}$, Kazuo Mishima ${ }^{4}$ and Fumio Yamamoto ${ }^{3}$

\begin{abstract}
Background: We aimed to estimate the prevalence of depressive symptoms as well as suicide-related ideation among Japanese university students during the stay-home order necessitated by the coronavirus disease 2019 pandemic in Japan, and offer evidence in support of future intervention to depression and suicide prevention strategies among college and university students.
\end{abstract}

Methods: The data for this cross-sectional study were derived from the Student Mental Health Survey conducted from May 20 to June 16, 2020 at a national university in Akita prefecture. Among the 5111 students recruited, 2712 participated in this study (response rate, 53\%; mean age \pm standard deviation, $20.5 \pm 3.5$ years; men, 53.8\%). Depressive symptoms were identified by using the Patient Health Questionnaire-9 (PHQ-9).

Results: The prevalence of moderate depressive symptoms based on a PHQ-9 score $\geq 10$ and suicide-related ideation based on question 9 of PHQ-9 $\geq 1$, which encompasses thoughts of both suicide and self-harm, was $11.7 \%$ and $6.7 \%$, respectively. Multivariable logistic regression analyses showed that risk factors for depression included being a woman, smoking, alcohol consumption, and social network communication using either video or voice. For suicide-related ideation, alcohol consumption was the only risk factor. Exercise and having someone to consult about worries were associated with decreased risk of both depressive symptoms and suicide-related ideation.

Conclusions: Negative lifestyles of smoking and drinking, and being a woman, may be important risk factors for depressive symptoms, whereas exercise and having someone to consult about worries may be protective factors.

Keywords: COVID-19 pandemic, Depressive symptoms, Stay-home order, Suicide-related ideation, University students

\footnotetext{
* Correspondence: knomura@med.akita-u.ac.jp

'Department of Environmental Health Science and Public Health, Akita

University Graduate School of Medicine, Akita, Japan

Full list of author information is available at the end of the article
}

(c) The Author(s). 2021 Open Access This article is licensed under a Creative Commons Attribution 4.0 International License, which permits use, sharing, adaptation, distribution and reproduction in any medium or format, as long as you give appropriate credit to the original author(s) and the source, provide a link to the Creative Commons licence, and indicate if changes were made. The images or other third party material in this article are included in the article's Creative Commons licence, unless indicated otherwise in a credit line to the material. If material is not included in the article's Creative Commons licence and your intended use is not permitted by statutory regulation or exceeds the permitted use, you will need to obtain permission directly from the copyright holder. To view a copy of this licence, visit http://creativecommons.org/licenses/by/4.0/. The Creative Commons Public Domain Dedication waiver (http://creativecommons.org/publicdomain/zero/1.0/) applies to the data made available in this article, unless otherwise stated in a credit line to the data. 


\section{Introduction}

The outbreak of the infectious coronavirus disease 2019 (COVID-19) was first reported in Wuhan, China, in December 2019, subsequently spreading to the extent of becoming a global pandemic. In Japan, the first case of COVID-19 was confirmed on January 15, 2020, and in March [1], the number of new cases sharply increased. In order to limit both the spread of the virus and overwhelming demands for medical care, on April 16, Japanese Prime Minister declared a nationwide state of emergency. Among the special measures against COVID-19 in Japan, the governor of each prefecture is empowered to call on residents to stay at home (selfquarantine) and refrain from going out. However, owing to the Japanese Constitution's emphasis on the protection of citizens' rights, a forced lockdown of cities through the imposition of fines on people going out without permission, as implemented in parts of Europe and the USA, was not possible. Nevertheless, educational institutions, restaurants, and public facilities were all closed, leaving cities and towns deserted.

Regarding the health consequences of the pandemic and subsequent isolation measures, depression is one of the most serious as it is closely linked with suicide. In Japan, according to Japanese vital statistics, in 2017, suicide was the first leading cause of death among individuals aged between 10 and 39, and the country's suicide rate is the highest among all G7 members [2]. Early evidence suggests the massive impact of lockdowns on psychological distress, with reports of high prevalence rates of depression, anxiety, and sleep disturbance [3-6]. A study in Belgium [7] reported that during the lockdown, young adults experienced a greater level of depression than their older counterparts, which may be explained by an intolerance of uncertainty. An Italian study [8] reported that the impact of the lockdown on psychological distress was greater in students than in workers. Thus, the health consequences of disasters differ by population subgroups, and it is clear that young adolescents are among the most vulnerable. Furthermore, given the high suicide rate in the younger generation in Japan, the psychological distress brought on by the COVID-19 pandemic may have been significant enough to affect students' mental health.

The rationale behind the closure of educational institutions was that young adolescents could contract COVID-19 and, owing to the high possibility of being asymptomatic, unknowingly carry and transmit the virus to the community. In this situation, the stay-home order left students who had traveled far from their hometowns to attend college and who were, therefore, alone in unfamiliar cities, completely alone. This was especially true for freshers, who were forbidden even to visit school, and had not yet had the opportunity to get to know their fellow students, resulting in temporary social withdrawal. Given the lack of Japan-specific data, with the aim of providing a reference for campus psychological services, this study sought to investigate depressive symptoms and suicide-related ideation in university students under the stay-home order and determine the risk and protective factors.

\section{Methods \\ Participants}

This cross-sectional study was a part of the Student Mental Health Survey that was conducted at Akita University between May 20 and June 16, 2020. As of May 16, 2020, 5111 graduate and undergraduate students were enrolled in Akita University. In Akita prefecture, while the self-quarantine period began on April 26 and officially ended on May 31, in reality, it continued until June 19 because all residents were strongly advised to refrain from going out or interacting with anyone, including family members, from beyond the boundary of the prefecture. Akita University contacted all students either by email or phone and confirmed that the majority were staying home. A very small number, however, had returned to their hometowns for urgent reasons (e.g., family health issues).

All students were approached via institutional emails and asked to log in to the e-classroom platform, where they would find a link to the online self-administered questionnaire. The first reminder for those who had not responded yet was sent 2 weeks after the initial email. Of the 2712 students enrolled in the study (response rate $53 \%$ ), we excluded those who had missing values on the Patient Health Questionnaire (PHQ-9, $n=257$ ). Accordingly, the data of 2449 students were analyzed.

This study was approved by the Institutional Review Board of Akita University Medical School (No. 2520). On the first page of the online self-administered questionnaire, students were given an explanation of the purpose of the study, the fact that participation was entirely voluntary, that they could withdraw from the study at any time without any repercussions with regard to their academic records, and that their data would be kept confidential. Subsequently, only interested students began answering the questionnaire. They were also provided with the opportunity to submit an opt-out withdrawal form, provided on the office of research administration website.

\section{Questionnaire}

A web-based survey composed of 51 multiple-choice questions was launched on May 20 and remained open until June 16 . The survey, which took approximately 15 min to complete, included questions on living arrangement (alone or living with family/others), hometown 
(within Akita or outside Akita), the presence of someone to consult about worries, smoking status (never, former, current), alcohol consumption (6-7 days/week, 3-4 days/week, 1-2 days/week, never), daily exercise (min per day), frequency of communication with people in their social networks (6-7 days/week, 3-4 days/week, 12 days/week, never), people they communicated with (family, friends, boy/girlfriends, acquaintances, strangers), the frequency of leaving the house for essential purposes, and worries about financial strain, academic attainment, health, social activity, and social support. Participants were asked to indicate which of the abovementioned five domains of worry they were most concerned about. Daily exercise was measured according to intensity-light (up to 4 metabolic equivalents (METS)), moderate (5-6 METS), vigorous (7-8 METS), and very vigorous (9-10 METS) - and multiplied with exercise time period and divided into quartiles (highest, second highest, second lowest, lowest). For communication with people in their social networks, the avenues considered were text (e.g., LINE, Twitter, Facebook), voice (e.g., telephone, iPhone, mobile phone, LINE), and video (e.g., Skype, LINE, ZOOM).

\section{PHQ-9}

Depressive symptoms were identified with the validated Japanese version of the PHQ-9 [9, 10], which was based on the nine criteria for depression proposed by the Diagnostic and Statistical Manual of Mental Disorders, 5th edition. Each item was rated on a four-point Likert scale ranging from 0 (not at all) to 3 (almost every day). PHQ-9 scores were divided into five groups representing varying levels of severity of depressive symptoms: 0-4 (minimal or none), 5-9 (mild), 10-14 (moderate), 15-19 (moderately severe), and 20-27 (severe). The total score ranged from 0 to 27 , and the higher the score, the more intense the depressive symptoms. Reliability, as depicted by Cronbach's alpha, was 0.86. The established PHQ-9 cutoff score of 10 (PHQ-9 $\geq 10$ ), which has previously demonstrated high sensitivity and specificity in detecting major depression was used [11, 12].

For suicide-related ideation, question 9 of the PHQ9, which encompasses thoughts of both suicide and self-harm [13], was used referring to previous literatures $[14,15]$. Participants were asked "Have you thought that you would be better off dead or of hurting yourself in some way?" The response received 0 for none, 1 for at least 2 days per week, 2 for at least 1 week, and 3 for nearly every day. Thus, the score of question $9 \geq 1$ was considered indicative of suiciderelated ideation. In our analyses, the score of question $9 \geq 1$ was treated as "suicide-related ideation" and the score of question $9 \geq 2$ was treated as "severe suiciderelated ideation."

\section{Statistical analysis}

First, we estimated the prevalence and 95\% confidence intervals (CIs) of depressive symptoms including suiciderelated ideation. Second, we conducted bivariable $\chi^{2}$ analysis to assess the association between demographic characteristics and depressive symptoms. Third, we used logistic regression to estimate odds ratios (ORs) and 95\% CIs for the association between each sociodemographic factor and depressive symptoms. Adjusting for covariates investigated in univariable models, multivariable logistic regression modeling was used to evaluate risk and protective factors for depressive symptoms. The statistical interaction between gender and other covariates was investigated.

All analyses were performed using STATA14-MP (Stata Corp LP, College Station, TX, USA). A two-sided $p$ value of $<0.05$ was considered statistically significant.

\section{Results}

Demographic characteristics were shown in Table 1. Of the 2449 students (mean age, $20 \pm 2$ years) included in the analyses, 757 (42\% women) were freshers, 504 (51\% women) were sophomores, 479 (51\% women) were juniors, 334 (53\% women) were seniors, 226 (30\% women) were graduate students, and 129 (50\% women) were classified as "others." The majority (86\%) of 1419 students who came from other prefectures lived alone. In total, $22 \%$ of the sample reported that they did not have anyone with whom they could discuss their worries, but this was more common in men than in women (see Table 1).

Prevalence of depressive symptoms and suicide-related ideation is shown in Table 2. Median with interquartile range of PHQ-9 was 3 with 0-6 in total, 2 with 0-6 in men, and 3 with 1-6 in women. In total, $11.6 \%$ of the sample scored $\geq 10$ on the PHQ-9, which was indicative of depressive symptoms (11.2\% of men; $12.0 \%$ of women) and $6.7 \%$ scored $\geq 1$ on question 9 of the PHQ-9 (6.7\% of men; $6.6 \%$ of women), which was indicative of suicide-related ideation. Men were more likely to have no depressive symptoms, whereas women were more likely to experience mild depressive symptoms.

Risk and protective factors for depressive symptoms are shown in Table 3 . The factors significantly associated with a PHQ- 9 score $\geq 10$ included being aged 20 years or older $(p=0.007)$, coming from other prefectures $(p=0.004)$, living alone $(p=0.002)$, low-intensity physical exercise $(p<0.001)$, being a current smoker $(p<0.001)$, frequent alcohol consumption $(p<0.001)$, social network communication using either sound or video $(p<0.001)$, worries about academic record and 
Table 1 Baseline characteristics of enrolled students $(n=2449)$

\begin{tabular}{|c|c|c|c|c|c|}
\hline & \multicolumn{2}{|c|}{ Men $(n=1308)$} & \multicolumn{2}{|c|}{ Women $(n=1119)$} & \multirow[t]{2}{*}{$p$} \\
\hline & $n$ & $\%$ & $n$ & $\%$ & \\
\hline Age, mean (sd) & $20(2)$ & & $20(2)$ & & 0.386 \\
\hline Hometown & & & & & $<0.001$ \\
\hline Outside Akita & 858 & 66 & 570 & 51 & \\
\hline Within Akita & 450 & 34 & 549 & 49 & \\
\hline Living alone & & & & & $<0.001$ \\
\hline Alone & 874 & 68 & 593 & 54 & \\
\hline Not alone & 420 & 32 & 513 & 46 & \\
\hline Exercise & & & & & $<0.001$ \\
\hline Highest quartile & 339 & 29 & 206 & 20 & \\
\hline Second highest quartile & 280 & 24 & 266 & 26 & \\
\hline Second lowest quartile & 270 & 23 & 282 & 28 & \\
\hline Lowest quartile & 280 & 24 & 256 & 25 & \\
\hline Smoking & & & & & $<0.001$ \\
\hline Current & 60 & 5 & 11 & 1 & \\
\hline Past & 45 & 3 & 13 & 1 & \\
\hline Never & 1204 & 92 & 1093 & 98 & \\
\hline Alcohol & & & & & $<0.001$ \\
\hline 5-7/week & 33 & 3 & 13 & 1 & \\
\hline 3-4/week & 60 & 5 & 28 & 3 & \\
\hline 1-2/week & 280 & 21 & 199 & 18 & \\
\hline Never-seldom & 931 & 71 & 877 & 79 & \\
\hline \multicolumn{6}{|c|}{ Social network service daily use } \\
\hline Text message & 1101 & 84 & 1052 & 94 & $<0.001$ \\
\hline Sound & 204 & 16 & 197 & 18 & 0.182 \\
\hline Video & 68 & 5 & 66 & 6 & 0.444 \\
\hline Either sound or video & 231 & 18 & 217 & 19 & 0.264 \\
\hline Worries & & & & & $<0.001$ \\
\hline Financial strain & 298 & 23 & 224 & 20 & \\
\hline Academic record & 313 & 24 & 253 & 23 & \\
\hline Leisure & 355 & 27 & 325 & 29 & \\
\hline Social support & 137 & 11 & 218 & 19 & \\
\hline Physical activity & 195 & 15 & 101 & 9 & \\
\hline Anyone to consult & & & & & $<0.001$ \\
\hline Yes & 957 & 73 & 934 & 83 & \\
\hline None & 346 & 27 & 187 & 17 & \\
\hline
\end{tabular}

The sum of the category that does not reach 2429 indicates missing values

social support $(p<0.001)$, and having no one to consult about worries $(p<0.001)$. The factors associated with a score $\geq 1$ on item 9 of the PHQ- 9 were lowintensity physical exercise $(p=0.006)$ and greater alcohol consumption $(p<0.001)$. Worries and having no one to consult were statistically associated with suicide-related ideation $(p=0.003$ and $p<0.001$, respectively).
Multivariable logistic regression analyses are shown in Fig. 1. Multivariable logistic regression analyses showed that being a woman (OR 1.45, 95\% CI, 1.07-1.94), current smoking (OR 2.85, 95\% CI, 1.48-5.50), weekly alcohol consumption frequency of 5-7 times (OR 2.45, 95\% CI, 1.09-5.50) and 3-4 times (OR 1.99, 95\% CI, $1.02-3.88)$, and daily social network communication using either voice or video (OR 1.71, 95\% CI, 1.22-2.40) were associated with an increased risk of depressive symptoms. Protective factors included exercise (highest quartile OR $0.54,95 \% \mathrm{CI}, 0.36-0.81$; second highest quartile OR $0.60,95 \% \mathrm{CI}, 0.41-0.89$; second lowest quartile OR $0.64,95 \% \mathrm{CI}, 0.44-0.93$, trend $p=0.002)$ and having someone to consult about worries (OR 0.24, 95\% CI, $0.18-0.32$ ). Statistical interaction was not observed between gender and any other covariates. Multivariable logistic regression models for the risk of suicide-related ideation are shown in a supplementary table. The risk factors included alcohol consumption at a weekly frequency of 5-7 times (OR 2.60,95\% CI, 1.03-6.55) and 3-4 times (OR 2.51, 95\% CI, 1.18-5.37) and worries (i.e., financial strain OR 2.79, 95\% CI, 1.13-6.89, academic record OR 3.05, 95\% CI, 1.25-7.44, social support OR 4.36, 95\% CI, 1.73-10.97 compared to physical activity). In contrast, the protective factors included exercise (highest quartile, OR 0.59, 95\% CI, 0.36-0.99), outside Akita (OR 0.61, 95\% CI, 0.38-0.96), and having someone to consult about worries (OR 0.20, 95\% CI, 0.14-0.29). Statistical interaction was not observed between gender and any other covariates.

\section{Discussion}

Although Japan did not enforce a strict lockdown like other countries, we still found that university students experienced psychological burden, with approximately $11 \%$ manifesting a moderate level of depressive symptoms, identified by a PHQ-9 score $\geq 10$. Negative lifestyles such as smoking and drinking, and being a woman, may be important risk factors for depressive symptoms, while exercise and having someone to consult about worries may be protective factors.

The prevalence of depression among college and university students under the COVID-19 pandemic varies depending on the diagnostic tools utilized, population in question, duration of quarantine/isolation, and how severely the areas in question have been affected [16]. However, in previous studies of college and university students using the PHQ-9, the following were the depression prevalence (PHQ-9 $\geq 10$ ) rates reported: $46.5 \%$ in the UK [17], 9.0\% in China [18], 18.5\% in Slovakia [19], and 31.7\% in Ukraine [20]. Although a direct comparison between countries is difficult, within Japan, a study [14] investigating the pre-pandemic situation among 2194 students at one national university reported 
Table 2 Prevalence of depressive symptoms and suicide related ideation

\begin{tabular}{|c|c|c|c|c|c|c|}
\hline & \multicolumn{2}{|l|}{ All $(n=2449)$} & \multicolumn{2}{|c|}{ Male $(n=1309)$} & \multicolumn{2}{|c|}{ Female $(n=1121)$} \\
\hline & $n(\%)$ & $95 \% \mathrm{Cl}$ & $n(\%)$ & $95 \% \mathrm{Cl}$ & $n(\%)$ & $95 \% \mathrm{Cl}$ \\
\hline \multicolumn{7}{|l|}{ PHQ-9 } \\
\hline None (0-4) & $1602(65.4 \%)$ & $63.5-67.3 \%$ & $904(69.1 \%)$ & $66.5-71.6 \%$ & $682(60.8 \%)$ & $57.9-63.7 \%$ \\
\hline Mild (5-9) & $564(23.0 \%)$ & $21.3-24.8 \%$ & $258(20.0 \%)$ & $17.6-22.0 \%$ & 304 (27.1\%) & $24.5-29.8 \%$ \\
\hline Moderate (10-14) & $191(7.8 \%)$ & $6.8-8.9 \%$ & $98(7.5 \%)$ & $6.1-9.1 \%$ & 93 (8.3\%) & $6.8-10.1 \%$ \\
\hline Moderately severe (15-19) & $57(2.3 \%)$ & $1.8-3.0 \%$ & $30(2.3 \%)$ & $1.6-3.3 \%$ & $26(2.3 \%)$ & $1.5-3.4 \%$ \\
\hline Severe $(\geq 20)$ & $35(1.4 \%)$ & $1.0-2.0 \%$ & $19(1.5 \%)$ & $0.9-2.3 \%$ & $16(1.4 \%)$ & $0.8-2.3 \%$ \\
\hline Moderate severe (10-) & $283(11.6 \%)$ & $10.3-12.9 \%$ & $147(11.2 \%)$ & $9.6-13.1 \%$ & $135(12.0 \%)$ & $10.2-14.1 \%$ \\
\hline Suicide-related ideation & $162(6.7 \%)$ & $5.7-7.7 \%$ & $88(6.7 \%)$ & $5.4-8.2 \%$ & $73(6.6 \%)$ & $5.2-8.2 \%$ \\
\hline Severe suicide-related ideation & $45(1.9 \%)$ & $1.4-2.5 \%$ & $21(1.6 \%)$ & $1.0-2.5 \%$ & $24(2.2 \%)$ & $1.4-3.2 \%$ \\
\hline
\end{tabular}

a $28.7 \%$ prevalence of depression (95\% CI, 27-31) based on PHQ-9 scores $\geq 5$. With the same diagnostic cutoff point (PHQ-9 $\geq 5$ ), the prevalence of depression among our population reached 34\% (95\% CI, 33-37), indicating a statistically higher prevalence [14]. Thus, the stayhome order appears to have been detrimental to students' psychological health.

In our study, we found that mild to moderate levels of depressive symptoms were more common in women than in men, but these differences disappeared with moderately severe to severe depressive symptoms and suicidal ideation. A meta-analysis of studies based on nationally representative samples in the USA suggested that generally, females have a high risk of depression; however, the higher depression prevalence in females than in males was observed only in early adolescence and gradually disappeared in adulthood [21]. A US study [22] on 1344 college students aged 18-29 years (12\% Asian) identified women are more likely to develop depressive symptoms (OR 1.99, 95\%CI, 1.07-2.90). However, this difference between genders disappeared with suicidal ideation which was consistent with our results. Among the few studies investigating suicidal ideation in college students globally, a study [23] on 33,635 students in grades 7-12 (13-18 years) in Beijing, China reported that the prevalence of suicidal ideation was significantly higher in girls (13.3\%) than boys (10.7\%). The difference between the study [23] and ours is probably attributed to the age differences of the samples in the two studies. While the mechanisms of higher depression prevalence in females remain unclear, the interplay of gender socialization, social and hormonal mechanisms, and stressful events associated with adolescence may play a role [24]. Alternatively, the absence of gender difference in suicidal ideation may be explained by the differences favoring men in suicide rates, where the rates among males were about three times those among females in Japan [25].
The present study demonstrated that unfavorable lifestyle habits, such as smoking and alcohol consumption, were associated with depressive symptoms. In a metaanalysis [26], nearly half of the 148 studies reported that baseline depression was associated with later smoking behavior, while over a third found evidence that exposure to smoking was associated with later depression. Although the direction mechanism of the relationship between smoking and depression is not clear, a causal mechanism usually requires a certain exposure period to cause illness. This may not have been possible in our young sample, where nearly half of the participants were under the age of 20 and therefore, prohibited by law from smoking or consuming alcohol. Hence, a reasonable interpretation of our findings may be that individuals started smoking or drinking after the onset of depressive symptoms. Indeed, depressive status is associated with increased vulnerability to substance use. The relationship between alcohol consumption and depressive symptoms in our study became stronger as weekly alcohol intake increased. It is well established that there are strong links between heavy alcohol consumption and mental health problems [27]. In addition, a study [28] reported that a reduced-nicotine standard for cigarettes may reduce smoking without worsening depressive symptoms, which is consistent with the results of longitudinal studies. This may suggest that quitting smoking leads to decreased recurrence of depression [29]. Future studies should seek to explore the reduction of smoking and alcohol consumption as a way to identify potential causal pathways between unfavorable lifestyles and depression.

In contrast, a favorable lifestyle choice-engaging in exercise-was associated with a decreased risk of depressive symptoms, with a dose-response relationship. This finding requires careful interpretation because in this cross-sectional study, we simultaneously investigated exposure and outcome. Students with depressive symptoms may refrain from engaging in exercise even 
Table 3 Risk and protective factors for depressive symptoms

\begin{tabular}{|c|c|c|c|c|c|c|c|c|c|c|c|c|c|c|c|}
\hline & \multicolumn{4}{|c|}{$\begin{array}{l}\text { Moderate-severe level } \\
\text { depression }\end{array}$} & \multirow[t]{3}{*}{$p$} & \multicolumn{4}{|c|}{$\begin{array}{l}\text { Suicide-related } \\
\text { ideation }\end{array}$} & \multirow[t]{3}{*}{$p$} & \multicolumn{4}{|c|}{$\begin{array}{l}\text { Severe suicide-related } \\
\text { ideation }\end{array}$} & \multirow[t]{3}{*}{$p$} \\
\hline & \multicolumn{2}{|l|}{$(+)$} & \multicolumn{2}{|l|}{$(-)$} & & \multicolumn{2}{|l|}{$(+)$} & \multicolumn{2}{|l|}{$(-)$} & & \multicolumn{2}{|l|}{$(+)$} & \multicolumn{2}{|l|}{$(-)$} & \\
\hline & $n$ & $\%$ & $n$ & $\%$ & & $n$ & $\%$ & $n$ & $\%$ & & $n$ & $\%$ & $n$ & $\%$ & \\
\hline Sex & & & & & 0.533 & & & & & 0.865 & & & & & 0.318 \\
\hline Women & 135 & 48 & 986 & 46 & & 73 & 45 & 1038 & 46 & & 24 & 53 & 1087 & 46 & \\
\hline Men & 147 & 52 & 1162 & 54 & & 88 & 55 & 1217 & 54 & & 21 & 47 & 1284 & 54 & \\
\hline Age & & & & & 0.009 & & & & & 0.138 & & & & & 0.060 \\
\hline$<20$ & 100 & 35 & 943 & 44 & & 60 & 37 & 975 & 43 & & 13 & 29 & 1022 & 43 & \\
\hline $20-$ & 182 & 65 & 1218 & 56 & & 102 & 63 & 1292 & 57 & & 32 & 71 & 1362 & 57 & \\
\hline Hometown & & & & & 0.004 & & & & & 0.226 & & & & & 0.642 \\
\hline Outside Akita & 189 & 67 & 1248 & 58 & & 88 & 54 & 1342 & 59 & & 28 & 62 & 1402 & 59 & \\
\hline Within Akita & 94 & 33 & 913 & 42 & & 74 & 46 & 926 & 41 & & 17 & 38 & 983 & 41 & \\
\hline Living alone & & & & & 0.002 & & & & & 0.745 & & & & & 0.505 \\
\hline Alone & 193 & 70 & 1281 & 60 & & 99 & 62 & 1368 & 61 & & 29 & 66 & 1438 & 61 & \\
\hline Not alone & 84 & 30 & 859 & 40 & & 60 & 38 & 876 & 39 & & 15 & 34 & 921 & 39 & \\
\hline Exercise & & & & & $<.001$ & & & & & 0.006 & & & & & 0.011 \\
\hline Highest quartile & 49 & 19 & 502 & 26 & & 28 & 19 & 484 & 24 & & 7 & 17 & 541 & 25 & \\
\hline Second highest quartile & 54 & 21 & 497 & 26 & & 30 & 21 & 518 & 25 & & 9 & 22 & 541 & 25 & \\
\hline Second lowest quartile & 62 & 24 & 492 & 25 & & 34 & 23 & 520 & 25 & & 6 & 15 & 546 & 25 & \\
\hline Lowest quartile & 93 & 36 & 447 & 23 & & 53 & 37 & 520 & 25 & & 19 & 46 & 518 & 24 & \\
\hline Smoking & & & & & $<.001$ & & & & & 0.009 & & & & & 0.003 \\
\hline Current & 19 & 7 & 52 & 2 & & 9 & 6 & 62 & 3 & & 5 & 11 & 66 & 3 & \\
\hline Past & 12 & 4 & 46 & 2 & & 8 & 5 & 50 & 2 & & 2 & 4 & 56 & 2 & \\
\hline Never & 252 & 89 & 2062 & 95 & & 145 & 90 & 2155 & 95 & & 38 & 84 & 2262 & 95 & \\
\hline Alcohol & & & & & $<.001$ & & & & & $<.001$ & & & & & $<0.001$ \\
\hline 5-7/week & 13 & 5 & 33 & 2 & & 9 & 6 & 37 & 2 & & 4 & 9 & 42 & 2 & \\
\hline 3-4/week & 16 & 6 & 73 & 3 & & 11 & 7 & 77 & 3 & & 6 & 13 & 82 & 3 & \\
\hline 1-2/week & 62 & 22 & 419 & 19 & & 28 & 17 & 452 & 20 & & 7 & 16 & 473 & 20 & \\
\hline Never seldom & 192 & 68 & 1631 & 76 & & 114 & 70 & 1697 & 75 & & 28 & 62 & 1783 & 75 & \\
\hline \multicolumn{16}{|c|}{ Social network service daily use } \\
\hline Either sound or video & 73 & 26 & 379 & 18 & $<.001$ & 37 & 23 & 411 & 18 & 0.1339 & 12 & 27 & 436 & 18 & 0.150 \\
\hline Worries & & & & & $<.001$ & & & & & 0.0025 & & & & & 0.303 \\
\hline Financial strain & 63 & 22 & 465 & 22 & & 39 & 24 & 487 & 22 & & 10 & 23 & 516 & 22 & \\
\hline Academic record & 80 & 28 & 492 & 23 & & 43 & 27 & 526 & 23 & & 12 & 27 & 557 & 23 & \\
\hline Leisure & 56 & 20 & 628 & 29 & & 36 & 22 & 642 & 28 & & 10 & 23 & 668 & 28 & \\
\hline Social support & 56 & 20 & 301 & 14 & & 35 & 22 & 321 & 14 & & 10 & 23 & 346 & 15 & \\
\hline Physical activity & 26 & 9 & 270 & 13 & & 8 & 5 & 287 & 13 & & 2 & 5 & 293 & 12 & \\
\hline \multicolumn{5}{|c|}{ Anyone to consult about worries } & $<.001$ & & & & & $<.001$ & & & & & $<0.001$ \\
\hline Yes & 148 & 52 & 1760 & 81 & & 75 & 46 & 1821 & 80 & & 24 & 53 & 1872 & 79 & \\
\hline None & 135 & 48 & 400 & 19 & & 87 & 54 & 446 & 20 & & 21 & 47 & 512 & 21 & \\
\hline
\end{tabular}

though it can improve their psychological status. Nevertheless, a meta-analysis of 51 randomized controlled trials [30] reported that exercise may be an effective therapy for treating depression in university students, while another meta-analysis [31] suggested that exercise is a promising treatment for depression 
Sex Women vs. Men

Age $<20$ vs. 20 -

Hometown outside Akita vs. within Akita

Living alone vs. living with someone

Exercise Second lowest quartile Second highest quartile

Highest quartile

Smoking Current

Past

Alcohol 5-7/week

3-4/week

$1-2 /$ week

Daily use of Social network by video or voice

Worries Financial strain

Academic record

Leisure

Social support

Anyone to consult
about worries

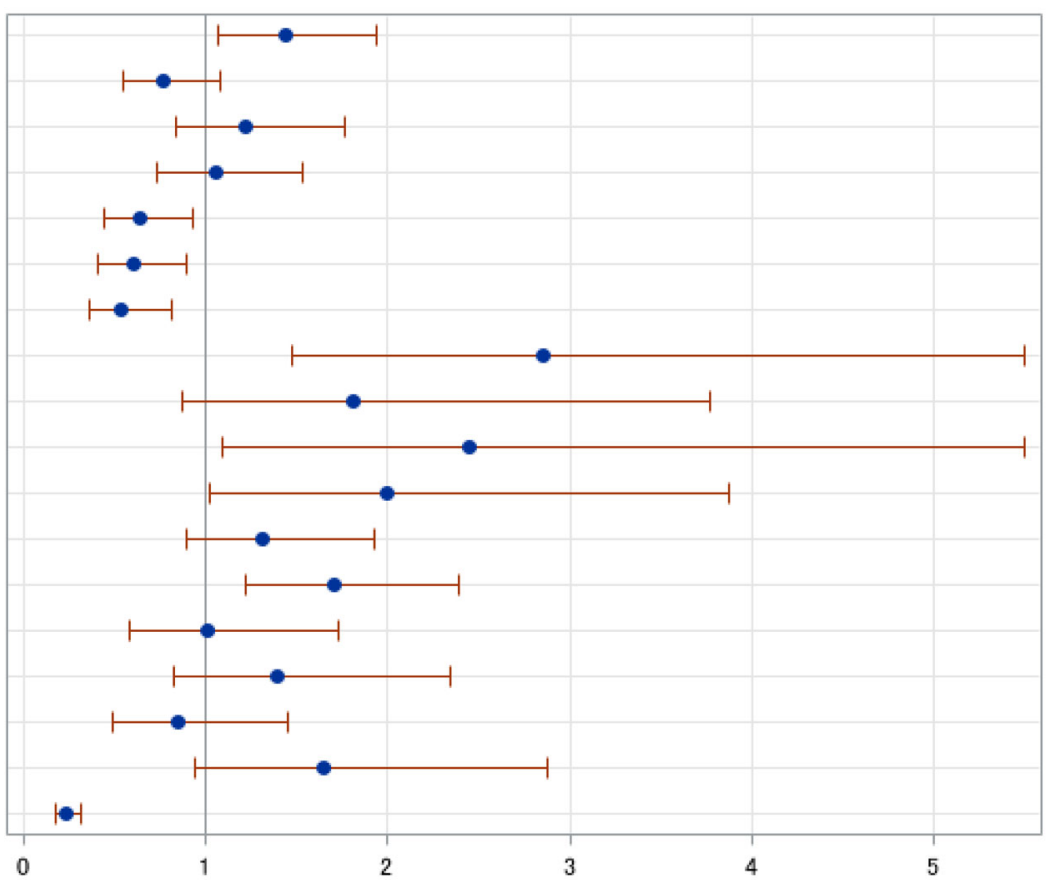

Odds ratio of Moderate-severe level depressive symptoms

Fig. 1 Factors associated with moderate-severe level depression

in adults, showing effects that are comparable to firstline treatments.

In the present study, it was found that daily social network communication using either video or voice was associated with depressive symptoms. The majority of the students who used video or voice features every day contacted their family, friends, and acquaintances, but 60 students used social networks for communication with unspecified people. Connecting with strangers on social networking platforms may be problematic because it does not involve the responsibility required in relationships, potentially leading to irresponsible and hurtful behavior [32]. In young users, this can be detrimental to academic achievement [33]. Consequently, these people may reduce their community participation, eventually becoming socially withdrawn, who are accompanied with psychomorbidity [34]. A study [35] that investigated 5972 students randomly selected from six universities in China demonstrated that poor social contact was significantly associated with an increased risk of suicidal ideation. We performed an additional analysis to determine if the 60 students connecting with strangers displayed an association with increased risk of suicide-related ideation but found no such trend. Although we were unable to determine whether daily use of video or voice communication tools was associated with internet addiction, in a previous study, internet addiction was significantly associated with psychiatric comorbidity, including depression
[36]. Further, a meta-analysis provides evidence that internet addiction is associated with increased suicidality even after adjusting for potential confounding variables including depression [37]. Nevertheless, the importance of internet addiction in this area of research needs further exploration. Although the cross-sectional design of this study posed a barrier to the determination of causality, the relationship between social network use (whether video or voice) and depression could be considered indicative of the fact that loneliness drives individuals to the active use of communication tools.

In our study, the presence of someone to consult about worries was associated with a decreased risk of depressive symptoms and suicide-related ideation. There is an abundance of evidence demonstrating that social support plays a major role in alleviating psychological distress. Factors such as family cohesion and connections with friends can play a protective role against suicidal behavior [38]. In our study, approximately $27 \%$ of men and $17 \%$ of women answered that they did not have anyone to consult about their worries. Help-seeking behavior, a powerful coping skill with regard to mental illness, can be difficult to learn [39]. Thus, there is a need for school intervention programs that cover protective skills in addition to self-care and social support from teachers, friends, and health or educational professionals.

Despite its strengths, this study has several limitations that need to be addressed. First, as the setting was a 
single university in Japan, the findings have limited generalizability. However, this limitation may be countered by the fact that the response rate exceeded $50 \%$ and the sample size was large. Second, the prevalence of depressive symptoms might have been underestimated because participation was voluntary. For example, students with depressive symptoms may have found it difficult to answer a 51-item questionnaire. In addition, some students may have hesitated to share their health information with the university despite the fact that we repeatedly explained that the purpose of the study was to screen high-risk individuals for prompt intervention. Third, owing to Japan's relatively low fatality rate, depressive symptoms may not have been very severe. In addition, even though a prefectural governor issued the request for people to stay indoors, they were still allowed to go out for essential purposes such as seeking medical care, purchasing necessary supplies, or commuting to an essential job. If the COVID-19 situation in Japan worsens, the severity and frequency of depressive symptoms may become more apparent. Fourth, because $85 \%$ of those who came from prefectures outside Akita lived alone, these two variables were highly correlated. To identify the problem of collinearity in multivariable regression analyses, we excluded those who lived alone or whose hometowns were outside Akita, but the results did not change. Finally, owing to the cross-sectional design, we were unable to make causal inferences regarding the relationships between variables.

\section{Conclusion}

We investigated depressive symptoms as well as suiciderelated ideation among Japanese university students during the COVID-19 stay-home order and found that negative lifestyles of smoking and drinking, and being a woman, may be important risk factors for depressive symptoms, whereas exercise and having someone to consult about worries may be protective factors.

\section{Abbreviations}

COVID-19: Coronavirus disease 2019; METS: Metabolic equivalents; PHQ9: Patient Health Questionnaire-9; OR: Odds ratio; Cl: Confidence interval

\section{Supplementary Information}

The online version contains supplementary material available at https://doi. org/10.1186/s12199-021-00953-1

Additional file 1:. sTable 1. Factors associated with suicide-related ideation.

\section{Acknowledgements}

We thank all students and faculties of Akita University for their understanding.

\section{Authors' contributions}

$\mathrm{KN}, \mathrm{KO}, \mathrm{TG}$, and $\mathrm{FY}$ conceived the study and $\mathrm{JH}, \mathrm{KR}$, and $\mathrm{SM}$ collected data. $\mathrm{KN}$ and EM performed statistical analyses and KM and MF interpreted psychological results. KN wrote the draft which was edited by SM and TI. All authors took responsibility for the integrity of the data and the accuracy of the data analysis. All the authors made critical revisions to the manuscript for important intellectual content and gave final approval of the manuscript.

Funding

Not applicable

\section{Availability of data and materials}

The datasets used and/or analyzed during the present study are available from the corresponding author on reasonable request.

\section{Declarations}

Ethics approval and consent to participate

This study was approved by the Institutional Review Board of Akita University Medical School (No. 2520). On the first page of the online self-administered questionnaire, students were given an explanation of the purpose of the study, the fact that participation was entirely voluntary, that they could withdraw from the study at any time without any repercussions with regard to their academic records, and that their data would be kept confidential. Subsequently, only interested students began answering the questionnaire. They were also provided with the opportunity to submit an opt-out withdrawal form, provided on the office of research administration website.

Consent for publication

Not applicable.

\section{Competing interests}

The authors declare that they have no competing interests.

\section{Author details}

${ }^{1}$ Department of Environmental Health Science and Public Health, Akita University Graduate School of Medicine, Akita, Japan. ${ }^{2}$ Department of Cell Physiology, Akita University Graduate School of Medicine, Akita, Japan. ${ }^{3}$ Akita University, Akita, Japan. ${ }^{4}$ Department of Neuropsychiatry, Akita University Graduate School of Medicine, Akita, Japan.

Received: 27 December 2020 Accepted: 23 February 2021

Published online: 05 March 2021

\section{References}

1. The Ministry of Health, Labour, and Welfare. Coronavirus disease (COVID-19) situation report in Japan. https://www.mhlw.go.jp/stf/covid-19/kokunainoha sseijoukyou.html. Accessed 29 Jan 2021

2. Organisation for Economic Cooperation and Development DATA. OECD Stat. 2021. https://data.oecd.org/healthstat/suicide-rates.htm. Accessed 29 Jan 2021

3. Ren X, Huang W, Pan H, Huang T, Wang X, Ma Y. Mental health during the Covid-19 outbreak in China: a meta-analysis. Psychiatr Q. 2020;91:1033-45. https://doi.org/10.1007/s11126-020-09796-5.

4. Groarke JM, Berry E, Graham-Wisener L, McKenna-Plumley PE, McGlinchey E, Armour C. Loneliness in the UK during the COVID-19 pandemic: crosssectional results from the COVID-19 Psychological Wellbeing Study. Plos One. 2020;15:e0239698.

5. Odriozola-González P, Planchuelo-Gómez Á, Irurtia MJ, de Luis-García R. Psychological effects of the COVID-19 outbreak and lockdown among students and workers of a Spanish university. Psychiatry Res. 2020;290: 113108 .

6. Pieh C, Budimir S, Probst T. The effect of age, gender, income, work, and physical activity on mental health during coronavirus disease (COVID-19) lockdown in Austria. J Psychosom Res. 2020;136:110186.

7. Glowacz F, Schmits E. Psychological distress during the COVID-19 lockdown: the young adults most at risk. Psychiatry Res. 2020;293:113486.

8. Marelli S, Castelnuovo A, Somma A, Castronovo V, Mombelli S, Bottoni D, et al. Impact of COVID-19 lockdown on sleep quality in university students and administration staff. J Neurol. 2020;1:1.

9. Kroenke K, Spitzer RL, Williams JBW. The PHQ-9: validity of a brief depression severity measure. J Gen Intern Med. 2001;16:606-13.

10. Muramatsu K, Kamijima K, Yoshida M, Otsubo T, Miyaoka H, Muramatsu Y, et al. The patient health questionnaire, Japanese version: validity according 
to the mini-international neuropsychiatry interview-plus. Psychol Rep. 2007; 101:952-60.

11. Du N, Yu K, Ye Y, Chen S. Validity study of Patient Health Questionnaire-9 items for Internet screening in depression among Chinese university students. Asia Pac Psychiatry. 2017;9:10. https://doi.org/10.1111/appy.12266.

12. Manea L, Gilbody S, McMillan D. Optimal cut-off score for diagnosing depression with the Patient Health Questionnaire (PHQ-9): a meta-analysis. CMAJ. 2012;184:E191.

13. Silverman MM, Berman AL, Sanddal ND, O'Carroll PW, Joiner TE. Rebuilding the tower of Babel: a revised nomenclature for the study of suicide and suicidal behaviors Part 2: Suicide-Related Ideations. Commun Behav. 2007; 37:264-77.

14. Mitsui N, Asakura S, Takanobu K, Watanabe S, Toyoshima K, Kako Y, et al. Prediction of major depressive episodes and suicide-related ideation over a 3-year interval among Japanese undergraduates. Sasayama D, editor. Plos One. 2018;13:e0201047.

15. Chow WS, Schmidtke J, Loerbroks A, Muth T, Angerer P. The relationship between personality traits with depressive symptoms and suicidal ideation among medical students: a cross-sectional study at one medical school in Germany. Int J Environ Res Public Health. 2018;15(7):1462. https://doi.org/1 0.3390/ijerph15071462

16. Henssler J, Stock F, van Bohemen J, Walter H, Heinz A, Brandt L. Mental health effects of infection containment strategies: quarantine and isolation - a systematic review and meta-analysis. Eur Arch Psychiatry Clin Neurosci. 2020;1:1.

17. Van Der Feltz-Cornelis CM, Varley D, Allgar VL, de Beurs E. Workplace stress, presenteeism, absenteeism, and resilience amongst university staff and students in the COVID-19 lockdown. Front Psychiatry. 2020;11:588803. https://doi.org/10.3389/fpsyt.2020.588803.

18. Tang W, Hu T, Hu B, Jin C, Wang G, Xie C, et al. Prevalence and correlates of PTSD and depressive symptoms one month after the outbreak of the COVID-19 epidemic in a sample of home-quarantined Chinese university students. J Affect Disord. 2020;274:1-7. https://doi.org/10.1016/j.jad.2020.05. 009.

19. Gavurova B, Ivankova V, Rigelsky M. Relationships between perceived stress, depression and alcohol use disorders in university students during the COVID-19 pandemic: a socio-economic dimension. Int J Environ Res Public Health. 2020;28(17):8853. https://doi.org/10.3390/ijerph17238853.

20. Rogowska AM, Pavlova I, Kuśnierz C, Ochnik D, Bodnar I, Petrytsa P. Does physical activity matter for the mental health of university students during the COVID-19 pandemic? J Clin Med. 2020;9(11):3494. https://doi.org/10.33 90/jcm9113494.

21. Salk RH, Hyde JS, Abramson LY. Gender differences in depression in representative national samples: meta-analyses of diagnoses and symptoms. Psychol Bull. 2017;143:783-822.

22. Polanco-Roman L, Anglin DM, Miranda R, Jeglic EL. Racial/ethnic discrimination and suicidal ideation in emerging adults: the role of traumatic stress and depressive symptoms varies by gender not race/ ethnicity. J Youth Adolesc. 2019;48:2023-37.

23. Zhang YY, Lei YT, Song Y, Lu RR, Duan JL, Prochaska JJ. Gender differences in suicidal ideation and health-risk behaviors among high school students in Beijing, China. J Glob Health. 2019;9:010604.

24. Cyranowski JM, Frank E, Young E, Shear MK. Adolescent onset of the gender difference in lifetime rates of major depression. A theoretical model. Arch Gen Psychiatry. 2000;57:21-7. https://doi.org/10.1001/archpsyc.57.1.21.

25. Ministry of Health, Labour and Welhare, Japan. Summary of Vital Statistics 2020. https://www.mhlw.go.jp/toukei/list/81-1.html

26. Fluharty M, Taylor AE, Grabski M, Munafò MR. The association of cigarette smoking with depression and anxiety: a systematic review. Nicotine Tob Res. 2017;19:3-13. https://doi.org/10.1093/ntr/ntw140.

27. Goodwin RD, Kim JH, Weinberger AH, Taha F, Galea S, Martins SS. Symptoms of alcohol dependence and smoking initiation and persistence: a longitudinal study among US adults. Drug Alcohol Depend. 2013;133:71823.

28. Tidey JW, Pacek LR, Koopmeiners JS, Vandrey R, Nardone N, Drobes DJ, et al. Effects of 6-week use of reduced-nicotine content cigarettes in smokers with and without elevated depressive symptoms. Nicotine Tob Res. 2017;19:59-67.

29. Bakhshaie J, Zvolensky MJ, Goodwin RD. Cigarette smoking and the onset and persistence of depression among adults in the United States: 19942005. Compr Psychiatry. 2015;60:142-8.
30. Huang J, Nigatu YT, Smail-Crevier R, Zhang X, Wang J. Interventions for common mental health problems among university and college students: a systematic review and meta-analysis of randomized controlled trials. J Psychiatr Res. 2018;107:1-10. https://doi.org/10.1016/j.jpsychires.2018.09.018.

31. Cooney GM, Dwan K, Greig CA, Lawlor DA, Rimer J, Waugh FR, et al. Exercise for depression: some benefits but better trials are needed. Cochrane Database Syst Rev. 2013;9:CD004366.

32. John A, Glendenning AC, Marchant A, Montgomery P, Stewart A, Wood S, et al. Self-harm, suicidal behaviours, and cyberbullying in children and young people: systematic review. J Med Internet Res. 2018;20:e129. https:// doi.org/10.2196/jmir.9044.

33. Van Den Eijnden R, Koning I, Doornwaard S, Van Gurp F, Ter Bogt T. The impact of heavy and disordered use of games and social media on adolescents' psychological, social, and school functioning. J Behav Addict. 2018:7:697-706

34. Yong R, Nomura K. Hikikomori is most associated with interpersonal relationships, followed by suicide risks: a secondary analysis of a national cross-sectional study. Front Psychiatry. 2019;10.

35. Tang F, Qin P. Influence of personal social network and coping skills on risk for suicidal ideation in Chinese university students. Pietschnig J, editor. Plos One. 2015;10:e0121023.

36. Ho RC, Zhang MWB, Tsang TY, Toh AH, Pan F, Lu Y, et al. The association between internet addiction and psychiatric co-morbidity: a meta-analysis. BMC Psychiatry. 2014;14:183.

37. Cheng Y-S, Tseng P-T, Lin P-Y, Chen T-Y, Stubbs B, Carvalho AF, et al. Internet addiction and its relationship with suicidal behaviors. J Clin Psychiatry. 2018;79:17r11761.

38. Biswas T, Scott JG, Munir K, Renzaho AMN, Rawal LB, Baxter J, et al. Global variation in the prevalence of suicidal ideation, anxiety and their correlates among adolescents: a population based study of 82 countries. EClinicalMedicine. 2020;24:100395.

39. Rowe SL, French RS, Henderson C, Ougrin D, Slade M, Moran P. Helpseeking behaviour and adolescent self-harm: a systematic review. Aust N Z J Psychiatry. 2014;48:1083-95.

\section{Publisher's Note}

Springer Nature remains neutral with regard to jurisdictional claims in published maps and institutional affiliations.

Ready to submit your research? Choose BMC and benefit from

- fast, convenient online submission

- thorough peer review by experienced researchers in your field

- rapid publication on acceptance

- support for research data, including large and complex data types

- gold Open Access which fosters wider collaboration and increased citations

- maximum visibility for your research: over $100 \mathrm{M}$ website views per year

At BMC, research is always in progress.

Learn more biomedcentral.com/submissions 